Original article

\title{
Preparation and in vitro characterisation of Ehrlichia ruminantium plasmid DNA and proteins encapsulated into and DNA adsorbed onto biodegradable microparticles
}

\author{
Ndavheleseni Tshikhudo ${ }^{\mathrm{a}, \mathrm{b}, *}$, Alri Pretorius ${ }^{\mathrm{a}}$, John Putterill ${ }^{\mathrm{a}}$, Mirinda van Kleef ${ }^{\mathrm{a}, \mathrm{b}}$ \\ a ARC-Onderstepoort Veterinary Institute, Onderstepoort, Pretoria, South Africa \\ ${ }^{\mathrm{b}}$ Dept. of Veterinary Tropical Diseases, Faculty of Veterinary Science, University of Pretoria, Pretoria, South Africa
}

\section{A R T I C L E I N F O}

\section{Article history:}

Received 25 June 2010

Received in revised form 5 August 2010

Accepted 6 August 2010

\section{Keywords:}

Microparticles

Single-dose

Heartwater

E. ruminantium

Prime-boost immunisations

\begin{abstract}
A B S T R A C T
Four E. ruminantium $1 \mathrm{H} 12$ open reading frames and their proteins known to protect sheep against heartwater needle challenge were encapsulated into, or adsorbed onto poly(D,L-lactide-co-glycolide) microparticles. Microspheres with smooth surface and smaller than $5 \mu \mathrm{m}$ diameters were produced, with high adsorption and encapsulation efficiencies. Gel electrophoresis showed that neither encapsulation nor adsorption affected the stability of the DNA or proteins. Cationic microparticles released $\sim 40 \%$ of plasmid DNA on day 1 while PLGA 50:50-COOH microparticles co-encapsulating plasmid DNA and polyvinyl alcohol only started to release from days $12-28$. Recombinant proteins were released from PLGA 85:15 and homopolymer R $203 \mathrm{~S}$ microparticles in a biphasic manner with a high initial burst release ( $\sim 45-80 \%)$. In contrast, PLGA 50:50 microparticles had low (15-65\%) initial burst release followed by (25-80\%) release by days (days $28-42$ ). A cocktail of these microparticles could therefore be used as single-dose auto-booster vaccine.
\end{abstract}

(c) 2010 Elsevier GmbH. All rights reserved.

\section{Introduction}

Since heartwater was first reported in sheep in the northern parts of South Africa (Provost and Bezuidenhout, 1987), it remains one of the major constraints to livestock production in areas dominated by ticks of the genus Amblyomma. The disease is caused by an intracellular parasite now known as Ehrlichia ruminantium. Currently, it is controlled by infecting animals with blood containing a mild Ball3 isolate, followed by treatment with tetracycline once a febrile reaction is detected (Yunker, 1996; Uilenberg et al., 1984). Neither this vaccine nor vaccination with attenuated (Jongejan, 1991) or inactivated heartwater organisms completely protects ruminants in the field possibly due to a lack in crossprotection between genotypes (Mahan et al., 1998). This underlines the need for an improved vaccine, preferably one which does not require cold storage as with the blood vaccine used in the infection and treatment method. A DNA vaccine consisting of a cocktail of 41 H12 open reading frames (ORFs) has been found to protect sheep against a homologous needle challenge using either 3 DNA inoculations (Pretorius et al., 2007) or alternatively, a DNA prime-recombinant $(\mathrm{r}) 1 \mathrm{H} 12$ protein boost vaccination strat-

\footnotetext{
* Corresponding author at: Onderstepoort Veterinary Institute, Private Bag X5, Onderstepoort 0110, South Africa. Tel.: +27 12529 9124; fax: +27 125299417.

E-mail address: tshikhudon@arc.agric.za (N. Tshikhudo).
}

egy (Pretorius et al., 2008). This approach was, however, not fully successful in the field. One way of improving the efficacy of the vaccine would be to use a different vaccine delivery strategy such as a biodegradable microparticle-based delivery system. A potential advantage of this system is that a single vaccination can mimic a prime-boost regimen. Microencapsulation technology was developed in the 1950s and is currently widely used with drugs of pharmaceutical importance (Morris et al., 1994). It has been reported that a single-dose of poly(D,L-lactide-co-glycolide) (PLGA) microparticles loaded with a DNA vaccine protected mice against Mycobacterium tuberculosis challenge at levels similar to 3 doses of naked DNA or $M$. bovis BCG (Cai et al., 2005). It has been reported that microparticles with diameters less than $10 \mu \mathrm{m}$, smooth surfaces, and a high pDNA/rprotein encapsulation efficiency are readily internalised by macrophages resulting in cellular immune responses (Hanes et al., 1997; Gupta et al., 1998). Such cell-mediated immune responses are necessary for immune protection against heartwater (Totté et al., 1999). Microparticles formulated to have sizes similar to the host pathogens can target the delivery of antigens to the appropriate antigen-presenting cells (APCs) such as dendritic cells (Jhunjhunwala et al., 2009; O'Hagan, 2006).

PLGA is the most studied biodegradable system. It is a polyester composed of one or more of 3 different hydroxy acid monomers, D-lactic, L-lactic, and/or glycolic acid (Morris et al., 1994; Jiang et al., 2005). The fact that PLGA is non-immunogenic, can encapsu- 
late antigens of virtually any size (O'Hagan et al., 1998; Jiang et al., 2005), can continuously release antigen for several months (Sah et al., 1995; Jiang et al., 2005), and adsorb DNA onto cationic microspheres make it suitable as a vaccine delivery system (Jilek et al., 2005). PLGA microspheres release their entrapped material in a polyphasic manner (biphasic or triphasic) (Sah et al., 1995). An initial burst release from surface pores is followed by a lag phase with minimum release and a second fast release phase as the matrix of the microspheres degrade (O'Hagan et al., 1998). A variety of release patterns for encapsulated vaccines can be pre-programmed by changing the microparticle size, molecular weight, and monomer ratio, and microparticles with different release rates can be combined as a single formulation (Morris et al., 1994; Feng et al., 2006). Medium-to-high polymer molecular weight and low antigen loading favours discontinuous, controlled release, whereas low polymer molecular weight and high antigen loading favours continuous release. PLGA polymers with 50:50 lactic acid:glycolic acid ratio take 50-90 days to completely bioerode in vivo. PLGA polymers with 85:15 monomer composition have biodegradation rate of 150 days while homopolymers such as poly(D,L-lactide) have a half-life of 12-14 months. High lactic acid content favours long lag release times (O'Hagan et al., 1998).

PLGA microparticles therefore offer the potential for the development of a single-dose heartwater vaccine since it is possible to predetermine and control the release time-point of adsorbed pDNA (Singh et al., 2003) or encapsulated vaccine components (O'Hagan et al., 1998; Cai et al., 2005). The main objective of this study was to develop microparticle formulations containing 150-220 $\mu \mathrm{g}$ plasmid DNA/rproteins capable of fast initial release of the 41 H12 ORFs followed by a second (day 21) and a third (day 42) boost releases of pDNA and protein antigen, respectively, to simulate a primary and booster vaccination administered as one single vaccine. In order to achieve this objective, we chose PLGA polymers with 50:50 monomer compositions to adsorb and encapsulate pDNA and low glycolic acid polymer as well as the homopolymer to encapsulate rproteins.

\section{Materials and methods}

\section{Materials}

Poly(D,L-lactide-co-glycolide) polymers were used: the hydrophilic polymer PLGA 50:50-COOH (RG $502 \mathrm{H}$ ), $12 \mathrm{kDa}$, inherent viscosity $0.16-0.24 \mathrm{dl} / \mathrm{g}$ and PLGA 50:50 (RG 504), $65 \mathrm{kDa}$, inherent viscosity $0.45-0.60 \mathrm{dl} / \mathrm{g}$ obtained from Boehringer Ingelheim (Germany) were used to adsorb pDNA and to encapsulate both pDNA and rproteins. PLGA 85:15, $20 \mathrm{kDa}$, inherent viscosity $0.50-0.65 \mathrm{dl} / \mathrm{g}$ used only for rprotein encapsulation was obtained from Polysciences, Inc., and the homopolymer poly(D,L-lactide) (PLA) (R $203 \mathrm{~S}$ ), $20 \mathrm{kDa}$, inherent viscosity $0.25-0.35 \mathrm{dl} / \mathrm{g}$ from Boehringer Ingelheim was only used to encapsulate rproteins.

\section{Large scale plasmid DNA isolation}

Four 1H12 ORFs (Erum2540, 2550, 2580, and 2590) (Collins et al., 2005) were previously cloned into the pCMViUBs mammalian expression vector (Collins et al., 2003). Plasmids were isolated after transforming the pCMViUBs_ORF constructs into TOP10 E. coli cells and growing overnight in $1000 \mathrm{ml}$ Luria-Bertani/ampicillin $(50 \mu \mathrm{g} / \mathrm{ml})$ broth. The plasmids were purified using NucleoBond ${ }^{\circledR}$ Xtra Maxi Plus kit, according to the instructions of the manufacturer. A sample of each of the pCMViUBs_ORF constructs was sequenced.

\section{Protein expression}

The 4 E. ruminantium $1 \mathrm{H} 12$ ORFs were previously cloned and expressed using the Invitrogen Champion ${ }^{\mathrm{TM}}$ pET Directional TOPO ${ }^{\circledR}$ Expression kit, according to the manufacturer's instructions (Pretorius et al., 2008). To improve levels of protein expression of rErum2540, the signal peptide sequence was removed. The forward primer specific for the rErum2540 ORF was redesigned downstream of the signal peptide (CACCACATACCAGAATGGGTATTCTG) and used with the previously designed reverse primer in a PCR catalysed by a proof reading polymerase (Pfu, Promega) that produces blunt-ended products. The PCR product was subcloned into the pET vector as described previously (Pretorius et al., 2008). Large-scale production of rproteins of all Erums were obtained by autoinduction of BL21 Star ${ }^{\mathrm{TM}}$ (DE3) bacterial cells in 11 of Overnight Express ${ }^{\mathrm{TM}}$ Instant $\mathrm{TB}$ Medium containing ampicillin $(50 \mu \mathrm{g} / \mathrm{ml})$ following electroporation in the BIORAD gene Pulser ${ }^{\circledR}$ II at $1.4 \mathrm{kV}$. The bacterial cells were incubated overnight at $37^{\circ} \mathrm{C}$ and rproteins were extracted from the cell pellet $(10,000 \times g, 10 \mathrm{~min})$ using the BugBuster ${ }^{\circledR}$ protein extraction reagent (Novagen ${ }^{\circledR}$ ). The extracted proteins were purified using the Protino ${ }^{\circledR}$ Ni-TED 1000 packed columns according to the manufacturer's instructions. The purified proteins were concentrated and urea removed by centrifugation at $4000 \times \mathrm{g}$ for $45 \mathrm{~min}$ using the Amicon ${ }^{\circledR}$ Ultra- 4 Centrifugal Filter Device (5000 MWCO, Millipore) and concentration determined using the bicinchoninic acid (BCA) protein assay (BCA1-1KT, Sigma-Aldrich). Proteins were resolved on sodium dodecyl sulphate polyacrylamide gel electrophoresis (SDS-PAGE) (Criterion ${ }^{\mathrm{TM}}$ XT Precast gel, 4-12\% Bis-Tris from BIORAD) and detected on Western blot with anti-His6 antibody (Roche) according to the instructions of the manufacturer.

\section{Microencapsulation of pDNA/rproteins}

Several parameters were optimised to find a procedure suitable to encapsulate both plasmid DNA and rproteins used in this study (Jeffery et al., 1993). To encapsulate each pDNA, an aqueous solution $(0.5-1 \mathrm{ml})$ consisting of $0.5-3 \mathrm{mg}$ of pDNA in Tris ethylenediaminetetraacetic acid (10 mM Tris-HCI, $1 \mathrm{M} \mathrm{Na} 2$ EDTA $\mathrm{pH} 8.5$ ) buffer supplemented with $2.5 \%$ polyvinyl alcohol (PVA) (MW 15000) was added dropwise into an organic phase solution of $100 \mathrm{mg}$ PLGA in $5 \mathrm{ml}$ dichloromethane (DCM). The mixture was sonicated (Branson 250 micro tip sonifier) for 1 min on ice to obtain a water-in-oil primary emulsion. The primary emulsion was added dropwise into $15-20 \mathrm{ml}$ aqueous solution of $0.03 \%$ PVA before being homogenised for 1 min using the Ultra-Turrax ${ }^{\circledR}$ homogeniser (Janke and Kunkel, IKA-Labortechnik). The formed microdroplets were hardened by stirring overnight at room temperature in $100 \mathrm{ml}$ solution of $0.03 \%$ PVA. Microparticles were collected and washed in distilled water by centrifuging 3 times at $10,000 \times g$ for $10 \mathrm{~min}$ and freeze-dried overnight using the Edwards freeze dryer. Microparticles were stored in desiccators at room temperature for 6 months. Recombinant proteins $(0.5-3 \mathrm{mg} / \mathrm{ml})$ were dissolved in phosphate buffered saline (PBS, pH 7.4) and encapsulated into all 4 polymers as mentioned above.

\section{Plasmid DNA adsorption onto microparticles}

An amount of $200 \mathrm{mg}$ of PLGA 50:50-COOH or PLGA 50:50 polymers dissolved in $10 \mathrm{ml}$ DCM was sonicated in TE buffer at a high speed to obtain a water-in-oil emulsion. To this emulsion, $50 \mathrm{ml}$ of $0.5 \%$ cetyltrimethylammonium bromide (CTAB) solution was added. The mixture was homogenised for $30 \mathrm{~s}$ and added to another $50 \mathrm{ml}$ of $0.5 \%$ CTAB solution to form a secondary emulsion. This emulsion was stirred overnight at $300 \mathrm{rpm}$ with a magnetic stirrer in an open beaker to evaporate the organic solvent. Hardened 
microparticles were washed twice in sterile water by centrifugation at $10,000 \times g$ for $10 \mathrm{~min}$. Freeze-dried microparticles $(100 \mathrm{mg})$ were incubated with $1 \mathrm{ml}$ TE buffer containing $500 \mu \mathrm{g}$ pDNA at $4{ }^{\circ} \mathrm{C}$ for $6 \mathrm{~h}$ on a platform shaker (Oster et al., 2005). Following centrifugation at $13,000 \times g$ for $10 \mathrm{~min}$, the supernatant was stored at $4{ }^{\circ} \mathrm{C}$ and the pellet freeze-dried.

Particle size and surface morphology as determined by scanning electron microscopy

A thin layer of Japan Gold Size artists resin was applied to an aluminium scanning electron microscope viewing stub and allowed to dry (air dry or oven dry) to a sticky, but not liquid consistency. Dried microparticles were then applied to the sticky surface of the stub using a fine (no. 1 or 2 ) artist paint brush. The stub was then tapped (side on) to dislodge any loose particles. The sample was sputter-coated with gold and viewed at $8 \mathrm{kV}$ using a Hitachi $\mathrm{S}-2500$ scanning electron microscope. Micrographs were taken at 300-3000× magnifications.

\section{Encapsulation and adsorption efficiency of pDNA}

The percentage of pDNA adsorbed relative to the amount of pDNA used during adsorption to PLGA 50:50-COOH was spectrophotometrically determined by measuring absorbance at $260 \mathrm{~nm}\left(A_{260}, \mathrm{~nm}\right)$ of the supernatant following adsorption and centrifugation at $13,000 \times g$ for $10 \mathrm{~min}$. Alternatively, the amount of adsorbed and encapsulated pDNA was determined by using an extraction technique (Barman et al., 2000). In this method, dried PLGA 50:50 microparticles (2.5-10 mg) were resuspended in equal amounts (200-500 $\mu \mathrm{l})$ of TE buffer and DCM in a 2-ml Eppendorf tube. After $90 \mathrm{~min}$ of end-to-end shaking at room temperature, the mixture was subjected to centrifugation at $13,000 \times \mathrm{g}$ for $5 \mathrm{~min}$, and the top aqueous layer containing the pDNA was removed. The amount of pDNA in the supernatant was measured spectrophotometrically.

Determination of in vitro release kinetics and stability of pDNA associated with microparticles

A total of $10-60 \mathrm{mg}$ of microparticles were incubated in duplicate in $1.5 \mathrm{ml}$ of TE buffer supplemented with $0.01 \%$ of Tween-80 as a wetting agent and $0.02 \%$ sodium azide as a bacteriostatic agent at $37^{\circ} \mathrm{C}$ for 21 days with rotation at $10 \mathrm{rpm}$. At predetermined time points (days $1,7,14$, and 21 ), the microparticles were subjected to centrifugation at $13,000 \times g$ for $10 \mathrm{~min}$ to separate the supernatant. All of the release media was sampled and replaced with an equivalent amount of fresh media. Microparticles were further incubated with rotation at $10 \mathrm{rpm}$ until the next sampling time point. The collected supernatants were stored at $-20^{\circ} \mathrm{C}$ until further use. The supernatant sample from extraction procedure and in vitro release were used in agarose gel electrophoresis to compare the stability to that of untreated pDNA. A total of $10-20 \mu l$ of pDNA sample mixed with loading dye was loaded onto $1 \%$ agarose gel containing $0.4 \mu \mathrm{g} / \mathrm{ml}$ ethidium bromide in TBE Buffer $(100 \mathrm{mM}$ Tris, $90 \mathrm{mM}$ boric acid, $1 \mathrm{mM}$ EDTA pH 8.4). The gel was run for $2 \mathrm{~h}$ at $80 \mathrm{~V} 140 \mathrm{~mA}$ and visualised using AutoChemi ${ }^{\mathrm{TM}}$ UVP BioImaging System.

Determination of protein loading $(P L)$ and encapsulation efficiency (EE)

To determine the amount of rproteins encapsulated, $4-30 \mathrm{mg}$ of microparticles were digested overnight in $1.5 \mathrm{ml}$ solution of $5 \%$ SDS in $0.1 \mathrm{M} \mathrm{NaOH}$. The resulting mixtures were centrifuged at
$13,000 \times g$ for $5 \mathrm{~min}$, and the supernatants were collected and analysed. Alternatively, $4-30 \mathrm{mg}$ of microparticles were dissolved in $1.5 \mathrm{ml} \mathrm{DCM}$ at $37^{\circ} \mathrm{C}$ for $10 \mathrm{~min}$. The proteins were extracted twice by addition of $400 \mu$ l distilled water followed by 5 min centrifugation at $13,000 \times g$. The aqueous top layers were pooled together and used in the BCA protein assay.

\section{Determination of in vitro protein release kinetics}

A Float-A-Lyzer ${ }^{\circledR}\left(100\right.$ kDa MWCO 3 ml capacity, Spectra/Por $\left.{ }^{\circledR}\right)$ was used for in vitro release kinetic studies (D'Souza and DeLuca, 2005). Preweighed amounts (10-60 mg) of protein-loaded freezedried microparticles were suspended in the release media $(12 \mathrm{mM}$ $\mathrm{NaH}_{2} \mathrm{PO}_{4} ; 75 \mathrm{mM} \mathrm{NaCI} ; 2 \mathrm{mM}$ urea, and $62 \mathrm{mM}$ imidazole $\mathrm{pH} 8$ ) supplemented with $5 \mathrm{mM}$ SDS as solubilising agent and $0.02 \%$ sodium azide as bacteriostatic agent. The samples were loaded into a Float-A-Lyzer ${ }^{\circledR}$ in duplicate and incubated at $37^{\circ} \mathrm{C}$ within a measuring cylinder filled with $25 \mathrm{ml}$ release media for 6 weeks. The release medium was continually stirred with a small magnetic stir bar at $2 \mathrm{rpm}$. At predetermined time points (once a week), $1 \mathrm{ml}$ release medium was collected and kept at $-20^{\circ} \mathrm{C}$. The collected supernatants were replaced with fresh medium, and the protein concentration in supernatant was determined using the BCA protein assay. The integrity of rprotein was confirmed by SDS-PAGE (Feng et al., 2006).

\section{Stability of encapsulated and released rproteins}

The stability of encapsulated rproteins was analysed by SDSPAGE. The alkaline hydrolysis supernatants and the in vitro release samples collected as mentioned above were used. A volume of $20 \mu \mathrm{l}$ was loaded onto a Criterion ${ }^{\mathrm{TM}}$ XT Precast gel, 4-12\% Bis-Tris from BIORAD at $100 \mathrm{~V}$ for $90 \mathrm{~min}$. Proteins were visualised after staining for $1 \mathrm{~h}$ with the PageSilver ${ }^{\mathrm{TM}}$ staining kit (Fermentas Life Sciences). In addition, less than $3 \mathrm{mg}$ of protein-loaded freeze-dried microparticles were soaked with $50 \mu \mathrm{l}$ of sample buffer for $5 \mathrm{~min}$ and $20 \mu \mathrm{l}$ loaded directly into the wells and subjected to electrophoresis as above. Possible degradation of encapsulated and released rprotein was investigated by Western blotting. The mouse monoclonal antibody for the detection of histidine-tagged rprotein (Ant-His6) from Roche was used.

\section{Results}

\section{Expression of rErum proteins in E. coli}

An amount of $2 \mathrm{mg}$ of each rprotein was required for encapsulation into the microparticles. The previously constructed plasmids containing the 4 ORFs (Erum2540, 2550, 2580, and 2590) were used for large-scale protein expression in E. coli. Removal of the signal peptide sequence from the rprotein expression vector drastically improved the expression of Erum2540 gene. All the rproteins were produced and had the correct MW as predicted from their cognate genes (Fig. 1). Three of the proteins were found predominantly in the insoluble fraction while rErum 2540 was mostly soluble. The amount of protein expressed differed with rErum2540 giving the highest yield $(\sim 5.5 \mathrm{mg} / \mathrm{ml})$ followed by rErum $2550(\sim 4 \mathrm{mg} / \mathrm{ml})$. Very little rErum 2580 and rErum 2590 were produced, and yields could not be improved using alternative E. coli strains such as BL21 (DE3) pLysS or Rosetta2 (DE3) or by incubating at lower temperatures. Expression was therefore repeated several times, and samples were pooled in order to obtain sufficient protein for encapsulation studies. 


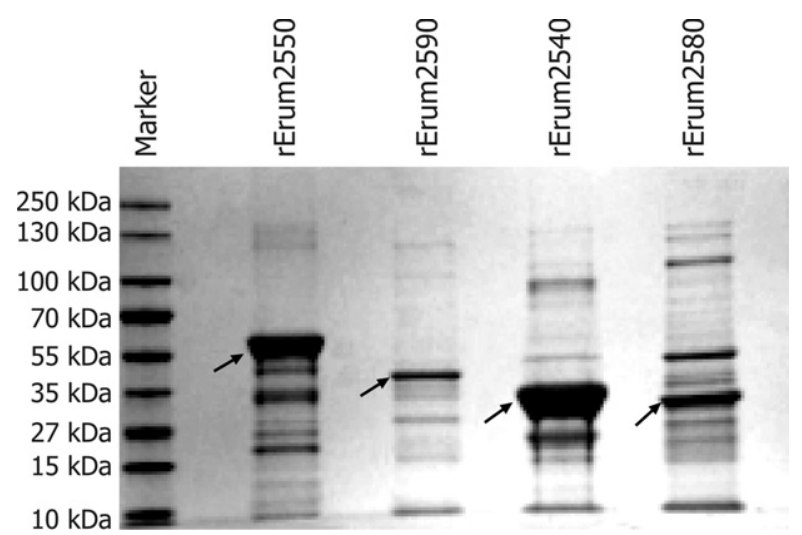

Fig. 1. A silver-stained SDS-PAGE gel of 4 rErum proteins expressed overnight in 11 of Overnight Express ${ }^{\mathrm{TM}}$ TB instant medium containing ampicillin. The arrows indicate the respective expressed rproteins of interest at the correct MW.

\section{Optimisation of size and surface morphology of microparticles}

Scanning electron microscopy was used to analyse the physical characteristics of the microparticles. All polymers formed a free-flowing powder of microparticles with various population sizes ranging from 0 to $2.5 \mu \mathrm{m}$ as represented by PLGA 50:50 (rErum2580) microparticles (Fig. 2). Most of the microparticles were below $1 \mu \mathrm{m}$ in diameter. The PLGA 50:50-COOH microparticles encapsulating pDNA were spherical, uniform, and smoother than those encapsulating rproteins (not shown). Cationic microparticles (microparticles with $0.5 \%$ CTAB on their surfaces) were denser and less than $1 \mu \mathrm{m}$ in diameter and also spherical in shape.

\section{Plasmid DNA encapsulation efficiency (EE) and adsorption} efficiency (AE)

Plasmid DNA of Erum2540, 2550, 2580, and 2590 was encapsulated into PLGA50:50-COOH and PLGA50:50 and the EE determined. The EE, which is a measure of the amount of pDNA incorporated into microparticles, was measured following disruption of the matrix by organic solvent. The EE ranged from 1.25 to $55.4 \%$, while the DNA loading expressed as the amount of pDNA per milligram of freeze-dried microparticles was $0.03-2 \mu \mathrm{g} / \mathrm{mg}$ (Table 1). The hydrophilic polymer PLGA 50:50- $\mathrm{COOH}$ was able to reach the highest EE of 55.4\% (Erum2550) and a DNA loading of $2 \mu \mathrm{g} / \mathrm{mg}$ (Erum2540) without further manipulation of the encapsulation protocol. However, PLGA 50:50 polymer needed addition of excipients such as gelatin, CTAB, or PVA in the internal water phase to improve its DNA loading from 0 to $0.125 \mu \mathrm{g} / \mathrm{mg}$ (Erum2590). Plasmid DNA of Erum2540, 2550, 2580, and 2590 was

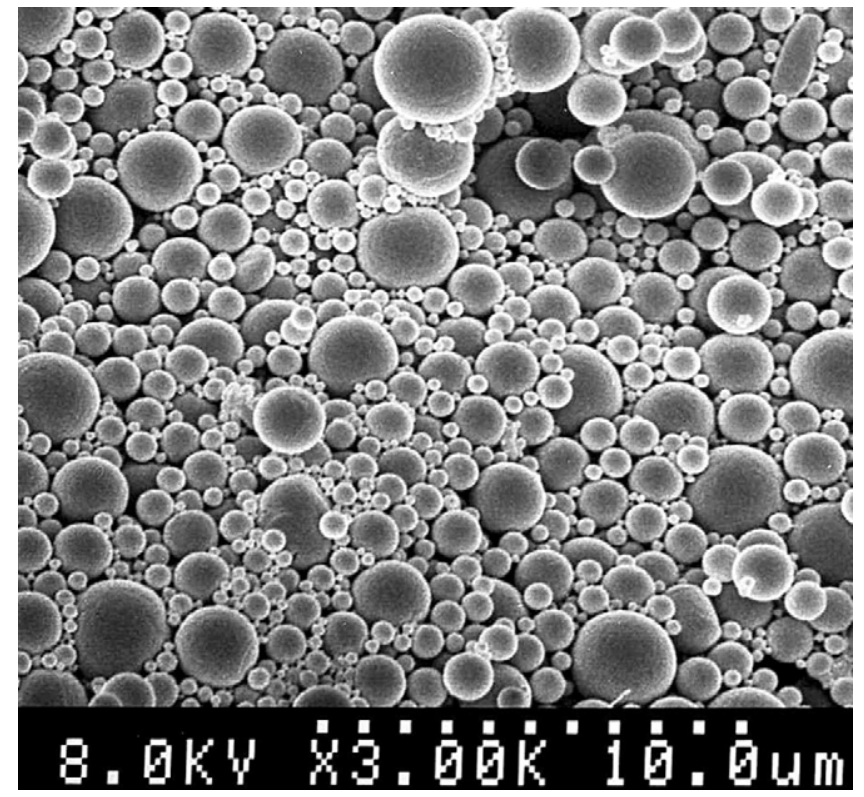

Fig. 2. SEM micrograph of PLGA 50:50 microparticles encapsulating rErum2580 insoluble protein. The micrograph represents the majority of microparticles formed by all polymers following the use of PVA as the internal viscosity enhancer.

adsorbed onto PLGA50:50-COOH and PLGA50:50 and the AE determined. The amount of pDNA adsorbed onto cationic microparticles (PLGA 50:50-COOH) was measured in the supernatant fraction that remained following adsorption of DNA and by DCM disruption of (PLGA 50:50) microparticles (Table 1). PLGA 50:50-COOH microparticles gave the targeted adsorption efficiency of $90-100 \%$ (i.e. $0.3-18 \mu \mathrm{g} / \mathrm{mg}$ ). In contrast, PLGA 50:50 gave low adsorption (51.3\%) and encapsulation (0.47\%) efficiencies when tested with Erum2550 and inconclusive results when tested with Erum2540, 2590, and 2580 (Table 1).

\section{Plasmid DNA integrity}

The integrity of pDNA encapsulated into and adsorbed onto PLGA 50:50-COOH microparticles were analysed using agarose gel electrophoresis following 6 months of storage in desiccators at room temperature (Fig. 3). DNA degradation manifested as smears in the gel was observed following its release from the microparticles (Fig. 3A). The release experiments were carried out in TE buffer, and any DNA degradation observed may be attributed to DNAses in buffer as no inhibitors were added. The open circular (OC) form of DNA was in excess of the supercoiled (SC) form following encapsulation suggesting that encapsulation did slightly

\section{(A): Encapsulated}

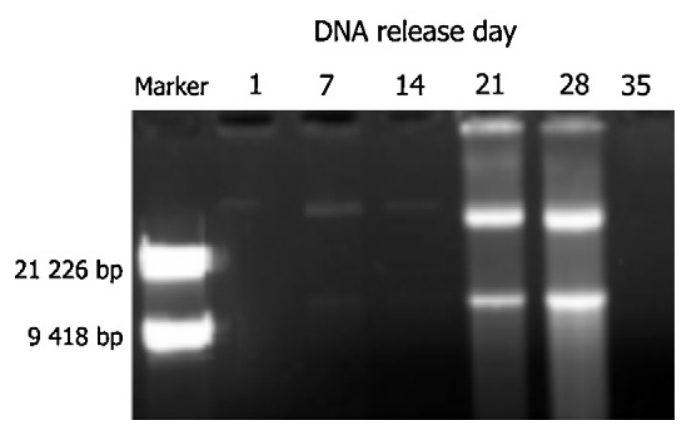

(B): Absorbed DNA

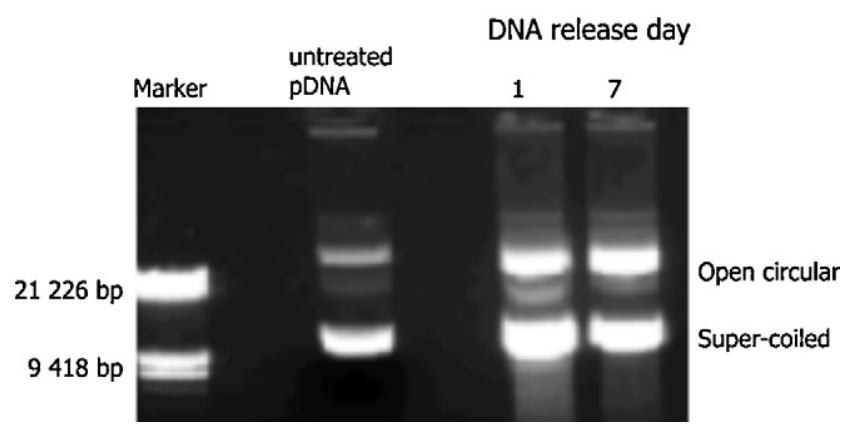

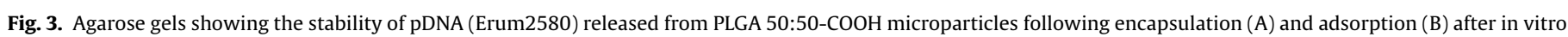
incubation in TE buffer ( $10 \mathrm{mM}$ Tris-HCI Na ${ }_{2}$ EDTA $1 \mathrm{M} \mathrm{pH} 8$ ) supplemented with $0.01 \%$ Tween-80 and $0.02 \%$ sodium azide at $37{ }^{\circ} \mathrm{C}$ with rotating on Stuart ${ }^{\circledR} \mathrm{SB} 3$ rotator. 

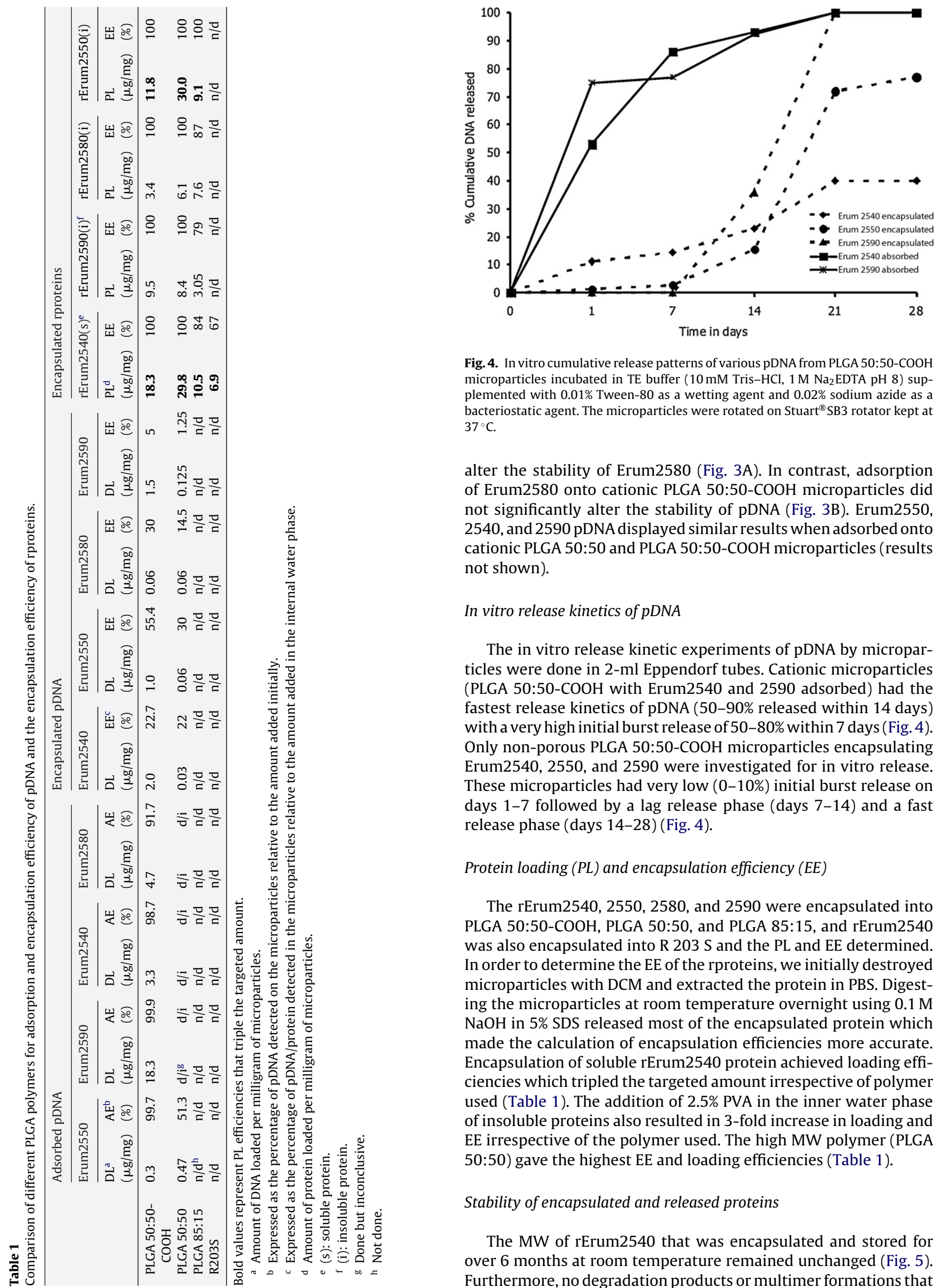

Fig. 4. In vitro cumulative release patterns of various pDNA from PLGA 50:50-COOH microparticles incubated in TE buffer $(10 \mathrm{mM}$ Tris- $\mathrm{HCl}, 1 \mathrm{M} \mathrm{Na} 2$ EDTA pH 8$)$ supplemented with $0.01 \%$ Tween- 80 as a wetting agent and $0.02 \%$ sodium azide as a bacteriostatic agent. The microparticles were rotated on Stuart ${ }^{\circledR}$ SB3 rotator kept at $37^{\circ} \mathrm{C}$.

alter the stability of Erum2580 (Fig. 3A). In contrast, adsorption of Erum2580 onto cationic PLGA 50:50-COOH microparticles did not significantly alter the stability of pDNA (Fig. 3B). Erum2550, 2540 , and 2590 pDNA displayed similar results when adsorbed onto cationic PLGA 50:50 and PLGA 50:50-COOH microparticles (results not shown).

In vitro release kinetics of $p D N A$

The in vitro release kinetic experiments of pDNA by microparticles were done in 2-ml Eppendorf tubes. Cationic microparticles (PLGA 50:50-COOH with Erum2540 and 2590 adsorbed) had the fastest release kinetics of pDNA (50-90\% released within 14 days) with a very high initial burst release of $50-80 \%$ within 7 days (Fig. 4). Only non-porous PLGA 50:50-COOH microparticles encapsulating Erum2540, 2550, and 2590 were investigated for in vitro release. These microparticles had very low $(0-10 \%)$ initial burst release on days 1-7 followed by a lag release phase (days 7-14) and a fast release phase (days 14-28) (Fig. 4).

\section{Protein loading $(P L)$ and encapsulation efficiency (EE)}

The rErum2540, 2550, 2580, and 2590 were encapsulated into PLGA 50:50-COOH, PLGA 50:50, and PLGA 85:15, and rErum 2540 was also encapsulated into R 203 S and the PL and EE determined. In order to determine the EE of the rproteins, we initially destroyed microparticles with DCM and extracted the protein in PBS. Digesting the microparticles at room temperature overnight using $0.1 \mathrm{M}$ $\mathrm{NaOH}$ in $5 \%$ SDS released most of the encapsulated protein which made the calculation of encapsulation efficiencies more accurate. Encapsulation of soluble rErum 2540 protein achieved loading efficiencies which tripled the targeted amount irrespective of polymer used (Table 1). The addition of 2.5\% PVA in the inner water phase of insoluble proteins also resulted in 3-fold increase in loading and EE irrespective of the polymer used. The high MW polymer (PLGA 50:50) gave the highest EE and loading efficiencies (Table 1).

\section{Stability of encapsulated and released proteins}

The MW of rErum2540 that was encapsulated and stored for over 6 months at room temperature remained unchanged (Fig. 5). Furthermore, no degradation products or multimer formations that 


\section{(A) PLGA 50:50-COOH}

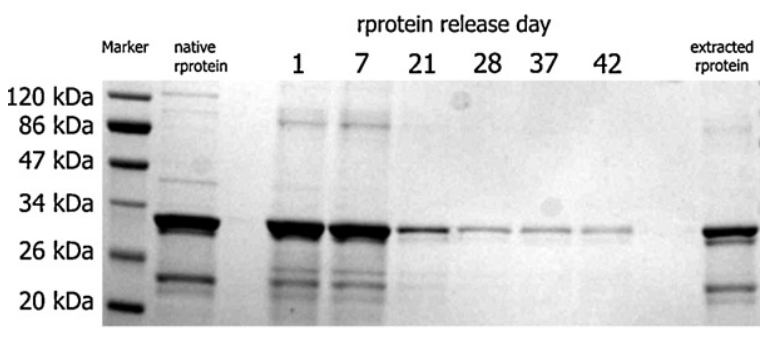

(B) PLGA 50:50

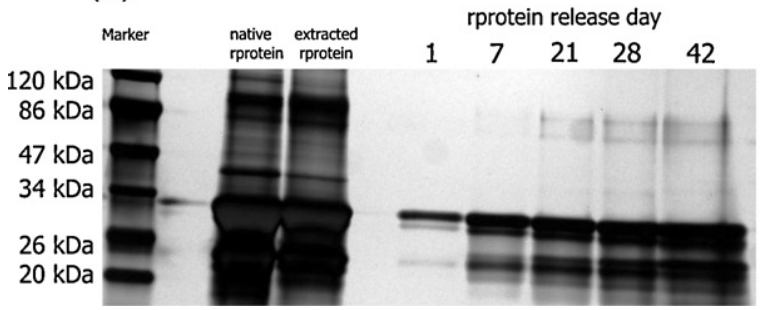

Fig. 5. Silver-stained SDS-PAGE gels showing the stability and intensity of rErum2540 insoluble rproteins released from either PLGA 50:50-COOH (A) or PLGA 50:50 (B) microparticles following $37^{\circ} \mathrm{C}$ incubation in Float-A-Lyzer ${ }^{\circledR}$ containing release medium ( $12 \mathrm{mM} \mathrm{NaH}_{2} \mathrm{PO}_{4}, 75 \mathrm{mM} \mathrm{NaCl}, 2 \mathrm{mM}$ urea, and $62 \mathrm{mM}$ imidazole pH 8 supplemented with $5 \mathrm{mM}$ SDS and $0.02 \%$ sodium azide). The extracted proteins were recovered from hydrolysed microparticles following 6 months of storage at room temperature.

could be attributed to encapsulation were detected on SDS-PAGE gels. Similar results were obtained with the 3 other rproteins. Western blots demonstrated that the proteins were not degraded by the microencapsulation process and in vitro release procedures when compared to the untreated protein (not shown). These results further indicate that microencapsulation did not detrimentally affect the stability of the encapsulated rproteins.

\section{In vitro protein release kinetics}

The in vitro release experiments were done to identify those microparticles that release proteins in a manner that mimics the DNA prime/rprotein boost vaccination strategy. They should have a low initial burst release and the release should continue beyond day 42 of in vitro incubation. A Float-A-Lyzer ${ }^{\circledR}$ was used to analyse the release of proteins from those microparticles which gave detectable protein loading efficiencies. To avoid rproteins aggregation and degradation during the release experiments, the following release medium was used $\left(12 \mathrm{mM} \mathrm{NaH}_{2} \mathrm{PO}_{4}, 75 \mathrm{mM} \mathrm{NaCl}, 2 \mathrm{mM}\right.$ urea, and $62 \mathrm{mM}$ imidazole $\mathrm{pH} 8$ ) supplemented with $5 \mathrm{mM}$ SDS as solubilising agent and $0.02 \%$ sodium azide as a bacteriostatic agent. Samples were taken from the release media at predetermined time points. The corresponding determined protein concentrations were plotted against time. The release profile of rErum 2540 and 2550 from PLGA 50:50-COOH microparticles was biphasic and characterised by $\sim 55-70 \%$ initial burst release (days $1-7$ ) with a further $\sim 10 \%$ release on days $28-42$ (Fig. 6 ). In contrast, the release of rErum2540 and rErum2550 from PLGA 50:50 was triphasic, being characterised by an initial burst release of ( $15-70 \%)$ due to protein adsorption and diffusion from microparticle surfaces followed by a slow release phase (days 7-28) and a second fast-release phase (days $28-42$ ) where $\sim 25-80 \%$ of protein was released. These release profiles were confirmed by the intensity of protein bands visualised by silver staining of SDS-PAGE gels (Fig. 5). PLGA 50:50 microparticles were visible in the Float-A-Lyzer ${ }^{\circledR}$ even after the termination of release experiments, thus showing signs of a slower bioerosion rate not observed with highly hydrophilic polymers (PLGA 50:50-

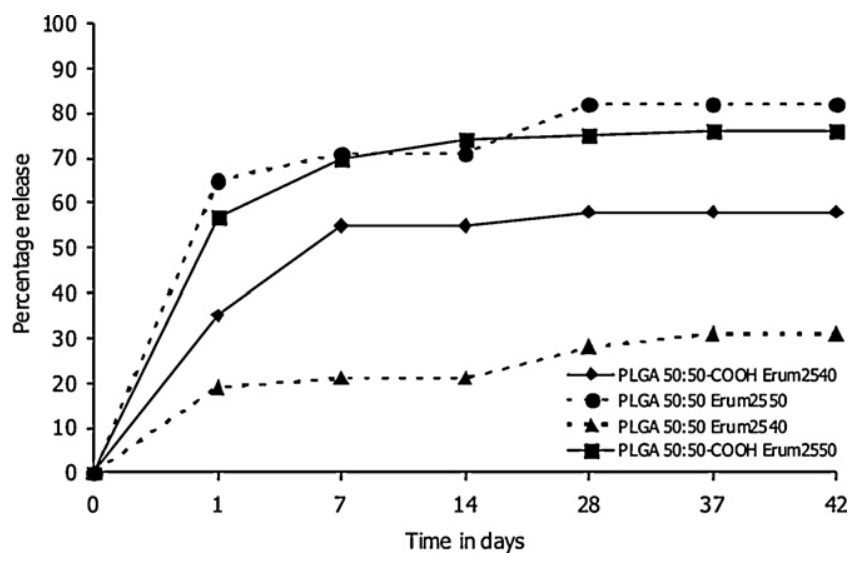

Fig. 6. The in vitro release kinetics of insoluble rproteins from microparticles loaded in Float-A-Lyzer ${ }^{\circledR}$ kept in buffer $\left(12 \mathrm{mM} \mathrm{NaH}_{2} \mathrm{PO}_{4}, 75 \mathrm{mM} \mathrm{NaCl}, 2 \mathrm{mM}\right.$ urea, and $62 \mathrm{mM}$ imidazole $\mathrm{pH} 8$ ) supplemented with $5 \mathrm{mM}$ SDS and $0.02 \%$ sodium azide at $37^{\circ} \mathrm{C}$ for 6 weeks. Samples $(1 \mathrm{ml})$ were taken weekly.

$\mathrm{COOH})$. The homopolymer R $203 \mathrm{~S}$ and low glycolic acid polymer PLGA 85:15 microparticles had the highest initial burst release of $45-80 \%$. The overall release of rErum 2540 from R $203 \mathrm{~S}$ and rErum2550 and 2590 from PLGA 85:15 microparticles was biphasic (Fig. 7).

\section{Discussion}

There is an urgent need to replace the blood vaccine that is commercially available to control heartwater in South Africa. Since its inception about 50 years ago, attempts based on the inactivated (Martinez et al., 1996) and attenuated live vaccines (Mahan et al., 1998; Shkap et al., 2007) gave some success but not good enough to replace it. The hope for an effective and stable vaccine shifted to genomics and proteomics to deliver a non-living vaccine that can also be used in rural areas where infrastructures are limited (Mwangi et al., 2002). Such a vaccine should be easy and cheap to produce and stable at room temperature (Purnell, 1984).

The main goal of this study was to develop microparticle formulations adsorbing or encapsulating the 4 1H12 ORFs and their gene products and release them in a way that mimic the prime-boost immunisation. These ORFs are known to provide protective immunity against a heartwater needle challenge in sheep (Pretorius et al., 2007, 2008). To achieve this, we developed a microencapsulation method that is capable of fast initial release of pDNA followed by a

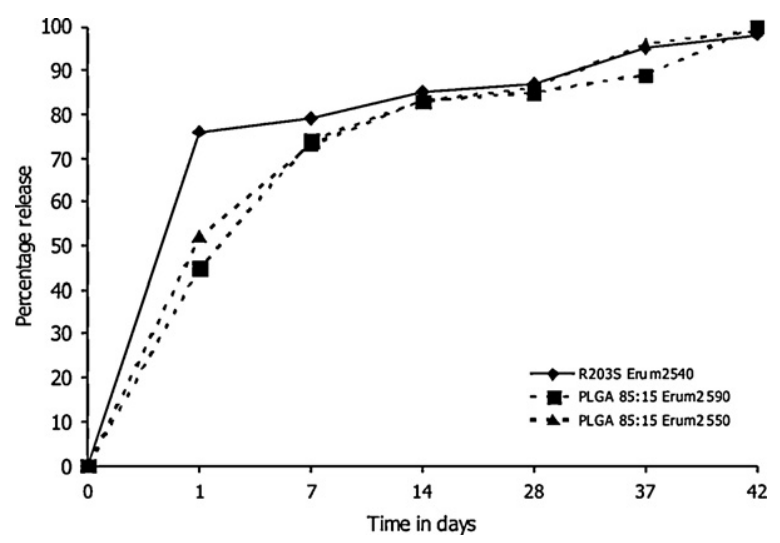

Fig. 7. In vitro release profiles of various insoluble rproteins from microparticles made of low glycolic acid polymers incubated in buffer $\left(12 \mathrm{mM} \mathrm{NaH}_{2} \mathrm{PO}_{4}, 75 \mathrm{mM}\right.$ $\mathrm{NaCl}, 2 \mathrm{mM}$ urea, and $62 \mathrm{mM}$ imidazole $\mathrm{pH} 8$ ) supplemented with $0.02 \%$ sodium azide and $5 \mathrm{mM}$ SDS in Float-A-Lyzer ${ }^{\circledR}$ kept at $37^{\circ} \mathrm{C}$ for 6 weeks. Samples $(1 \mathrm{ml})$ were taken weekly. 
second wave of DNA and a third wave of protein release. Moreover, we were able to show by gel electrophoresis that our microencapsulation method would be able to stabilize the protein antigen as well as the DNA to ensure that it will not degrade prior to its release a few weeks after vaccination.

One concern for DNA vaccine production is the nature of the immunogenic pDNA (Díez and Tros de Ilarduya, 2006; Jilek et al., 2005; Cooke et al., 2004; Pillai et al., 2008). Plasmid DNA exists in one of 3 main forms, namely SC, OC, and linear. Because the $\mathrm{SC}$ form is very compact and less prone to enzymatic degradation in host cells, it is the most efficient in transfections. Pillai et al. (2008) have demonstrated a 3-times increase in transfection efficiency when using SC pDNA in mice injected intramuscularly when priming MVA-boosted $\mathrm{CD}^{+} \mathrm{T}$-cells. Another report indicated that the higher transfection efficiency of SC pDNA may be due to its ability to enter the perinuclear region more effortlessly than the OC and linear forms (Lavelle et al., 1999). In this study, the SC topology was the most dominant form after $24 \mathrm{~h}$ of in vitro incubation of cationic microparticles. Adsorption of pDNA onto microparticles avoids exposure of pDNA to extreme preparation conditions such as sonication, organic solvent, etc. (Hanes et al., 1997; Díez and Tros de Ilarduya, 2006). This accounts for cationic microparticles having the highest proportion of SC pDNA compared to pDNA encapsulated into microparticles. Adsorption of pDNA onto microparticles is therefore preferred over encapsulation. Agarose gel electrophoresis showed that our microparticles preserve the SC and OC nature of the pDNA following adsorption or encapsulation. Adsorption of pDNA resulted in more of the SC form than obtained with encapsulation, and this should be taken into account when developing a vaccine. The amount of released SC DNA should be the same for each 'boost', and therefore almost double the amount of encapsulated pDNA is needed to yield a similar proportion of SC pDNA as was released by adsorbed microparticles.

The quality of protein antigen determines the magnitude of immune responses towards that particular antigen (Feng et al., 2006; Hanes et al., 1997; Lavelle et al., 1999). The integrity of the protein after encapsulation in microparticles was assessed by SDSPAGE followed by silver staining. Again, our results showed that the microencapsulation method developed here is capable of preserving the integrity of protein antigen prior to its release after vaccination. These results showed that microencapsulation could be the answer to the challenge of stability (at room temperature) that is faced by the current heartwater commercial vaccine.

Micrographs taken using scanning electron microscope showed that our freeze-dried microparticles formed a free-flowing powder with a heterogeneous population of microspheres with smooth surface morphology as well as diameters of less than $5 \mu \mathrm{m}$. The use of a sonicator as opposed to using a homogeniser to prepare the primary emulsion and the addition of PVA did not only result in microparticles of the desired size, but also improved the surface texture of microparticles made with PLGA 50:50-COOH and insoluble rproteins that were initially pitted with minor dimples on their surfaces. PLGA 85:15 and R 203 S microparticles did not need PVA to improve their size and surface morphology but to improve their encapsulation and loading efficiencies. Adsorption of pDNA onto the PLGA 50:50-COOH cationic microparticles resulted in an increase in diameter of the particles from 1 to $4 \mu \mathrm{m}$. This is still within the required size range to make them potential targets for APCs. There is an overwhelming number of reports that show that microparticle size plays an important role during transfection with pDNA (Prabha et al., 2002; Scheerlinck and Greenwood, 2008; Heit et al., 2008; Audran et al., 2003). Prabha et al. (2002) have shown that smaller nanoparticles $(\sim 70 \mathrm{~nm})$ had a transfection rate 27 -fold higher than that of larger nanoparticles $(\sim 97 \mathrm{~nm})$ and therefore a concomitantly higher potential to induce cellmediated immunity. Such cell-mediated immune responses are necessary for immune protection against heartwater (Totté et al., 1999).

The hydrophilic polymer PLGA 50:50-COOH adsorbed a lot more pDNA than PLGA 50:50. This polymer released majority of adsorbed pDNA within day 1 of in vitro incubation and could therefore be used to prime an immune response in vivo. PLGA 50:50-COOH encapsulated pDNA was released from weeks 2 to 3 of in vitro incubation and could serve to boost an immune response. In general, the in vitro release experiments indicated that we were able to form microparticles that release pDNA almost each week of incubation using PLGA 50:50-COOH polymer.

In contrast, PLGA 50:50 encapsulated more rproteins than other polymers, and the release was characterised by the lowest initial burst release and could be the most suitable polymer to provide rproteins needed to boost immune response. The triphasic release profile displayed by PLGA 50:50 microparticles makes them good candidates to provide the booster immunisation needed to evoke a secondary immune response (Giteau et al., 2008). This could lead to a prolonged supply of proteins to the immune system (Heit et al., 2008). The polyphasic release is regarded as the most effective regimen in the design of vaccine formulations (Giteau et al., 2008; Sah et al., 1995). However, the proteins close to the surface of these microparticles need to be extracted by leaching microparticles in buffer before the in vivo administration to get rid of any burst release (Whittlesey and Shea, 2004). Unlike PLGA 50:50-COOH, PLGA 50:50 microparticles were visible in the Float-A-Lyzer ${ }^{\circledR}$ even after the termination of release experiments. This is a sign of slower bioerosion rate of the latter polymer (Lavelle et al., 1999).

In future, we will test these microparticles in sheep and compare the efficacy to that evoked by a naked vaccine. A cocktail of these microparticles could consequently function as a single-dose vaccine against heartwater in sheep.

\section{Acknowledgements}

We are grateful for the help provided by I. Sebatjane and $\mathrm{N}$. Thema during rprotein expression and Dr. D. du Plessis and Dr. A. Mather for critically reading the manuscript. This work was funded by the South African Department of Agriculture, Forestry and Fisheries.

\section{References}

Audran, R., Peter, K., Dannull, J., Men, Y., Scandella, E., Groettrup, M., Gander, B., Corradin, G., 2003. Encapsulation of peptides in biodegradable microspheres prolongs their MHC Class-I presentation by dendritic cells and macrophages in vitro. Vaccine 21, 1250-1255.

Barman, S.P., Lunsford, L., Chambers, P., Hedley, M.L., 2000. Two methods for quantifying DNA extracted from poly(lactide-co-glycolide) microspheres. J. Control. Release 69, 337-344.

Cai, H., Hu, X.D., Yu, D.H., Li, S.X., Tian, X., Zhu, Y.X., 2005. Combined DNA vaccine encapsulated in microspheres enhanced protection efficacy against Mycobacterium tuberculosis infection of mice. Vaccine 23, 4167-4174.

Collins, N.E., Liebenberg, J., De Villiers, E.P., Brayton, K.A., Louw, E., Pretorius, A., Faber, F.E., van Heerden, H., Josemans, A., van Kleef, M., Steyn, H.C., van Strijp, M.F., Zweygarth, E., Jongejan, F., Maillard, J.C., Bertheir, D., Botha, M., Joubert, F., Corton, C.H., Thomson, N.R., Allsopp, M.T., Allsopp, B.A., 2005. The genome of the heartwater agent Ehrlichia ruminantium contains multiple tandem repeats of actively variable copy number. Proc. Natl. Acad. Sci. U.S.A. 102, 838-843.

Collins, N.E., Pretorius, A., van Kleef, M., Brayton, K.A., Allsopp, M.T., Zweygarth, E., Allsopp, B.A., 2003. Development of improved attenuated and nucleic acid vaccines for heartwater. Dev. Biol. (Basel) 114, 121-136.

Cooke, J.R., McKie, E.A., Ward, J.M., Keshavarz-Moore, E., 2004. Impact of intrinsic DNA structure on processing of plasmids for gene therapy and DNA vaccines. J. Biotechnol. 114, 239-254.

Díez, S., Tros de Ilarduya, C., 2006. Versatility of biodegradable poly(D,L-lactic-coglycolic acid) microspheres for plasmid DNA delivery. Eur. J. Pharm. Biopharm. 63, 188-197.

D’Souza, S.S., DeLuca, P.P., 2005. Development of a dialysis in vitro release method for biodegradable microspheres. AAPS Pharm. Sci. Technol. 6, 323-328.

Feng, L., Qi, X.R., Zhou, X.J., Maitani, Y., Wang, S.C., Jiang, Y., Nagai, T., 2006. Pharmaceutical and immunological evaluation of a single-dose hepatitis B vaccine using PLGA microspheres. J. Control. Release 112, 35-42. 
Giteau, A., Venier-Julienne, M.C., Aubert-Pouessel, A., Benoit, J.P., 2008. How to achieve sustained and complete protein release from PLGA-based microparticles? Int. J. Pharm. 350, 14-26.

Gupta, R.K., Singh, M., O’Hagan, D.T., 1998. Poly(lactide-co-glycolide) microparticles for the development of single-dose controlled-release vaccines. Adv. Drug Deliv. Rev. 32, 225-246.

Hanes, J., Cleland, J.L., Langer, R., 1997. New advances in microsphere-based singledose vaccines. Adv. Drug Deliv. Rev. 28, 97-119.

Heit, A., Busch, D.H., Wagner, H., Schmitz, F., 2008. Vaccine protocols for enhanced immunogenicity of exogenous antigens. Int. J. Med. Microbiol. 298, 27-32.

Jeffery, H., Davis, S.S., O'Hagan, D.T., 1993. The preparation and characterization of poly(lactide-co-glycolide) microparticles. II. The entrapment of a model protein using a (water-in-oil)-in-water emulsion solvent evaporation technique. Pharm. Res. 10, 362-368.

Jiang, W., Gupta, R.K., Deshpande, M.C., Schwendeman, S.P., 2005. Biodegradable poly(lactic-co-glycolic acid) microparticles for injectable delivery of vaccine antigens. Adv. Drug Deliv. Rev. 57, 391-410.

Jilek, S., Merkle, H.P., Walter, E., 2005. DNA-loaded biodegradable microparticles as vaccine delivery systems and their interaction with dendritic cells. Adv. Drug Deliv. Rev. 57, 377-390.

Jhunjhunwala, S., Raimondi, G., Thomson, A.W., Little, S.R., 2009. Delivery of rapamycin to dendritic cells using degradable microparticles. J. Control. Release 133, 191-197.

Jongejan, F., 1991. Protective immunity to heartwater (Cowdria ruminantium infection) is acquired after vaccination with in vitro-attenuated rickettsiae. Infect. Immun. 59, 729-731.

Lavelle, E.C., Yeh, M.K., Coombes, A.G., Davis, S.S., 1999. The stability and immunogenicity of a protein antigen encapsulated in biodegradable microparticles based on blends of lactide polymers and polyethylene glycol. Vaccine 17, 512-529.

Mahan, S.M., Kumbula, D., Burridge, M.J., Barbet, A.F., 1998. The inactivated Cowdria ruminantium vaccine for heartwater protects against heterologous strains and against laboratory and field tick challenge. Vaccine 16, 1203-1211.

Martinez, D., Perez, J.M., Sheikboudou, C., Debus, A., Bensaid, A., 1996. Comparative efficacy of Freund's and Montanide ISA50 adjuvants for the immunisation of goats against heartwater with inactivated Cowdria ruminantium. Vet. Parasitol. 67, 175-184.

Morris, W., Steinhoff, M.C., Russell, P.K., 1994. Potential of polymer microencapsulation technology for vaccine innovation. Vaccine 12, 5-11.

Mwangi, D.M., McKeever, D.J., Nyanjui, J.K., Barbet, A.F., Mahan, S.M., 2002. Immunisation of cattle against heartwater by infection with Cowdria ruminantium elicits T-lymphocytes that recognise major antigenic proteins 1 and 2 of the agent. Vet. Immunol. Immunopathol. 85, 23-32.

O'Hagan, D.T., 2006. Microparticles as vaccine delivery systems. In: Virgil, E.J.C., Schijns, D.R., O'Hagan, D.T. (Eds.), Immunopotentiators in Modern Vaccines. Academic Press, London, pp. 123-147.
O’Hagan, D.T., Singh, M., Gupta, R.K., 1998. Poly(lactide-co-glycolide) microparticles for the development of single-dose controlled-release vaccines. Adv. Drug Deliv. Rev. 32, 225-246.

Oster, C.G., Kim, N., Grode, L., Barbu-Tudoran, L., Schaper, A.K., Kaufmann, S.H.E., Kissel, T., 2005. Cationic microparticles consisting of poly(lactide-co-glycolide) and polyethylenimine as carriers systems for parental DNA vaccination. J. Control. Release 104, 359-377.

Pillai, V.B., Hellerstein, M., Yu, T., Amara, R.R., Robinson, H.L., 2008. Comparative studies on in vitro expression and in vivo immunogenicity of supercoiled and open circular forms of plasmid DNA vaccines. Vaccine 26, 11361141.

Prabha, S., Zhou, W.Z., Panyam, J., Labhasetwar, V., 2002. Size-dependency of nanoparticle-mediated gene transfection: studies with fractionated nanoparticles. Int. J. Pharm. 244, 105-115.

Pretorius, A., Collins, N.E., Steyn, H.C., van Strijp, F., van Kleef, M., Allsopp, B.A. 2007. Protection against heartwater by DNA immunisation with four Ehrlichia ruminantium open reading frames. Vaccine 25, 2316-2324.

Pretorius, A., van Kleef, M., Collins, N.E., Tshikhudo, N., Louw, E., van Strijp, F., Allsopp, B.A., 2008. A heterologous prime/boost immunisation strategy protects against virulent $E$. ruminantium Welgevonden needle challenge but not against tick challenge. Vaccine 26, 4363-4371.

Provost, A., Bezuidenhout, J.D., 1987. The historical background and global importance of heartwater. Onderstepoort J. Vet. Res. 54, 165-169.

Purnell, R.E., 1984. Control of heartwater in cattle in Southern Africa using terramycin/LA. Prev. Vet. Med. 2, 239-254.

Sah, H., Toddywala, R., Chien, Y.W., 1995. Continuous release of proteins from biodegradable microcapsules and in vivo evaluation of their potential as a vaccine Adjuvant. J. Control. Release 35, 137-144.

Scheerlinck, J.P., Greenwood, D.L., 2008. Virus-sized vaccine delivery systems. Drug Discov. Today $13,882-887$.

Shkap, V., de Vos, A.J., Zweygarth, E., Jongejan, F., 2007. Attenuated vaccines for tropical theileriosis, babesiosis and heartwater: the continuing necessity. Trends Parasitol. 23, 420-426.

Singh, M., Ugozzoli, M., Briones, M., Kazzaz, J., Soenawan, E., O'Hagan, D.T., 2003. The effect of CTAB concentration in cationic PLG microparticles on DNA adsorption and in vivo performance. Pharm. Res. 20, 247-251.

Totté, P., Bensaid, A., Mahan, S.M., Martinez, D., McKeever, D.J., 1999. Immune responses to Cowdria ruminantium infections. Parasitol. Today 15, 286290.

Uilenberg, G., Barré, N., Camus, E., Burridge, M.J., Garris, G.I., 1984. Heartwater in the Caribbean. Prev. Vet. Med. 2, 255-267.

Whittlesey, K.J., Shea, L.D., 2004. Delivery systems for small molecule drugs, proteins, and DNA: the neuroscience/biomaterial interface. Exp. Neurol. 190, 1-16.

Yunker, C.E., 1996. Heartwater in sheep and goats: a review. Onderstepoort J. Vet. Res. 63, 159-170. 